\title{
LA DISCRIMINACIÓN RACIAL A LAS COMUNIDADES NEGRAS: ANÁLISIS DESDE EL DIARIO EL UNIVERSAL DE CARTAGENA, COLOMBIA
}

Jesús Natividad Pérez Palomino ${ }^{1}$ Neidy Gutiérrez Soza ${ }^{2}$

\section{Resumen}

Este artículo abordó las noticias relacionadas con las comunidades negras, principalmente referidas a la discriminación racial y racismo en la sección "Cartagena", cronológicamente dos años (2012 y 2013). La sección "Cartagena", la segunda en importancia en el diario El Universal, donde se recogen las principales problemáticas de la ciudad.

Este análisis del discurso de los textos escritos, se ha basado en la realidad de las comunidades negras y cómo asumen el abordaje de estas noticias, principalmente la discriminación racial. Además de la concepción que tienen los periodistas, igualmente los líderes y lideresas de la comunidad.

Entre los resultados se identificó que los periodistas del diario El Universal, tienen conocimientos generales sobre lo que es el racismo y la discriminación racial establecida en tres categorías tales como: desprecio, rechazo y exclusión. En el período de la investigación, el Diario Universal en la sección Cartagena desarrolló 67 noticias relacionadas con la comunidad negra de las cuales solamente 9 abordaron sobre la discriminación racial.

Palabras clave: Discriminación racial, racismo, afrodescendientes, El Universal, comunidad negra, Cartagena, periodista, prejuicios y estereotipos.

\section{Summary}

This article addressed the news related to black communities, mainly regarding racial discrimination and racism in the "Cartagena" section, based chronologically on two years: 2012 and 2013. The "Cartagena" section is the second largest in the newspaper El Universal, where the main problems of the city are collected.

1 Máster en Comunicación Intercultural y Medio, Antropólogo y Gestor cultural en Palenque de San Basilio, Colombia. Correo electrónico: botrokolo@gmail.com

2 Master en Antropología Social y Coordinadora de Investigación y Postgrado en URACCAN - Bluefields, Tutora de la Investigación para optar el título de Máster en comunicación intercultural y medio, URACCAN. Correo electrónico: neidygs@yahoo.com 
This discourse analysis of written texts, has been based on the realities of black communities and how they assume these news, particularly racial discrimination. As well as the conception that the journalists and leaders from the community have.

Among the results we identified that the journalists of the newspaper El Universal, have general knowledge about what is racism and racial discrimination, and it's established in three categories such as: hatred, rejection and exclusion. In the period of investigation, the Universal Newspaper in Cartagena section developed 67 news related to the black community of which only 9 addressed information on racial discrimination.

Keywords: Racial discrimination, racism, Afrodescendants, El Universal, black community, Cartagena, journalist, prejudices and stereotypes.

\section{Introducción}

Cartagena es la capital del departamento de Bolívar, en Colombia. Está localizada en el Caribe, y fue uno de los puertos más importantes de América y el mayor punto de comercio de esclavos africanos en la época colonial. Actualmente, los sectores económicos más importantes de la ciudad son la industria, especialmente la petroquímica, el turismo y el comercio. La población afrodescendientes representa proporcionalmente más de un tercio de la población de Cartagena.

El observatorio contra la discriminación y racismo del Ministerio del Interior de Colombia, ha manifestado que Cartagena "es la ciudad del país donde más se discrimina, especialmente a la población de raza negra". Generalmente se hace por el color de piel de la persona, por su edad, el género, por ser gitano, lesbiana, gay, bisexual, transexual, discapacitado, de bajos recursos, entre otros. La discriminación en Cartagena es múltiple, y la ciudad ha sido protagonista por hechos bastante lamentables.

Por lo anterior, el presente artículo muestra el grado de conocimiento de los periodistas sobre la discriminación racial y racismo a las comunidades negras, mediante el acercamiento con los líderes y lideresas de las comunidades de la ciudad de Cartagena. Así mismo, analiza las noticias y cómo el abordaje de estas expresan la discriminación racial, el racismo y sus diversos estereotipos y prejuicios.

\section{Revisión de literatura}

Discriminación racial y racismo es una práctica de desconocimiento que ejerce el ser humano con relación al otro, para someter al otro por su condición religiosa, política, fenotípica, género, entre otras. Ésta surge por la construcción de conceptos de superioridad basados en intereses culturales, económicos, políticos y religiosos que argumenta su posición en la práctica del etnocentrismo (Restrepo \& Rojas, 2010; Alsina, 2001). 
En relación al racismo, el planteamiento de Van Dijk (2001), argumenta que éste está compuesto por dos subsistemas; uno social y otro cognitivo. El primero, que es racismo social, que es micro porque las prácticas son locales, y macro por el abuso de poder de las instituciones y organizaciones dominantes. El segundo es la concepción de racismo cognitivo, es cuando se presupone representaciones mentales socialmente compartidas y negativamente orientadas, desde una mirada más psicológica y de análisis individual.

Asimismo Van Dijk (2001), muestra cómo se aplica un nuevo racismo, el cual quiere ser más democrático y respetable, negando la existencia del mismo, que solo está en la derecha extrema e imponente que mantienen el poder político y económico de la sociedad. En definitiva se entiende que "el racismo es un prejuicio que se basa en distinciones físicas socialmente significativas. [Por lo tanto], racista es aquel que cree que ciertos individuos son superiores o inferiores a otros en virtud de estas diferencias", (Giddens, 2000).

El análisis del discurso, permite la complejidad de la discriminación racial en la ciudad de Cartagena y una lectura crítica del diario El Universal. Por lo tanto, para Van Dijk (1999) "el análisis crítico del discurso es un tipo de investigación analítica sobre el discurso que estudia primariamente el modo en que el abuso del poder social, el dominio y la desigualdad son practicados, reproducidos, y ocasionalmente combatidos, por los textos y el habla en el contexto social y político".

Asimismo, la "colonialidad" como fenómeno histórico coadyuva a las élites, en los pueblos que han estado sometidos al colonialismo, a mantener sus jerarquías territoriales, políticas, culturales y epistémicas reproduciendo y reafirmando el enfoque de dominador y dominado (Restrepo \& Rojas, 2010). Para estos dos investigadores el colonialismo y la colonialidad son dos procesos diversos. Donde el primero tiene que ver con el sometimiento político y militar para adelantar el momento de explotación de trabajo y riquezas a las colonias. Y el segundo a un fenómeno más complejo que se extiende hasta la actualidad y perdura en la mente de las personas.

La Comunicación intercultural establece lo siguiente: “...cualquier comunicación podría definirse como intercultural” (Alsina, 2001). Parto de esta premisa porque afirma que la comunicación, en cualquier medio o lugar es intercultural, entendiendo que, la interculturalidad "significa la relación entre diferentes culturas; en nuestro contexto se refiere a las relaciones entre los pueblos originarios y afrodescendientes con las sociedades hegemónicas." (Del Cid, 2010).

Entender la comunicación intercultural, permite responder a la dinámica cultural de los pueblos, que paulatinamente reconocen que los cambios y la transformación de la identidad, se lleven a cabo. El problema de la identidad es una discusión que ha sido única y exclusivamente de la sociedad moderna. 
Los estereotipos y prejuicios son las diferencias fenotípicas de las personas, que según León, la categoría raza es el "término cultural, no biológico, que permite clasificaciones históricamente determinadas de los individuos de acuerdo con concepciones socioculturales" (León, 2012). Esta afirmación evidencia los distintos comportamientos de las personas, el proceso de relacionamiento entre sí.

\section{Materiales y métodos}

Esta investigación se realizó en la ciudad de Cartagena de Indias, Colombia, con la participación de seis periodistas del diario El Universal de Cartagena con sus diversos artículos escritos en la sección denominada "Cartagena". Además, los nueve líderes y lideresas que presiden las organizaciones de base en las comunidades afrodescendientes, que son parte de la plataforma del Cabildo de Integración Social "Gavilaneo"3 que fueron parte activa de esta investigación.

La metodología de la investigación se desarrolló desde la perspectiva cualitativa (Goetz \& LeCompte, 1988) e hizo énfasis en el análisis del discurso como plantea Van Dijk (1999), que se basa en el análisis de los textos escritos en los medios de comunicación y plantea el debate sobre cómo éstos pueden reproducir los enfoques de dominación por medio de la discriminación racial.

Las técnicas correspondieron a entrevistas abiertas a los periodistas, conversaciones formales e informales a los líderes. También, la revisión documental de la sección Cartagena del diario El Universal en el período comprendido entre el 2012 a 2013 para realizar el análisis de contenidos de las noticias.

\section{Resultados y discusión}

\section{Una Cartagena de afrodescendientes, que poco a poco se autoreconoce}

La ciudad de Cartagena, fue el principal puerto de desembarque de los hombres y mujeres que fueron traídos por la trata esclavista desde el siglo XVI hasta más allá de la cuarta parte del siglo XIX. En este puerto, en el período colonial, la venta y compra de las personas africanas fue lo que económicamente permitió dar un dinamismo comercial. Como argumento para imponer su explotación, se desconoció sus manifestaciones culturales, y por sus rasgos fenotípicos y la tez de su piel se le denominó seres inferiores, para mercantilizarlos.

3 El cabildo de integración social "Gavilaneo", es una plataforma de organizaciones de comunidades negras-afrodescendientes, que tiene su radio acción en la ciudad Cartagena y departamento de Bolívar. Su principal objetivo es exigibilidad de los derechos, por medio de la aplicación y puesta en marcha de la política pública. Las organizaciones que lo conforman son de Jóvenes, Mujeres, Consejos Comunitarios, Asociaciones de Etnoeducadores, organizaciones culturales, sociales, ambientales entre otras. 
Es menester recordar, que Cartagena fue una de las tres sedes donde se instaló la inquisición impuesta por la iglesia católica, la cual juzgaba a las personas que de acuerdo con sus lecturas eran paganas, practicaban religiones distintas a la católica, cristina y romana.

Fueron muchas las almas de las personas que fenecieron, durante este período, por el trabajo forzado que estaban obligados a desarrollar, por la búsqueda de la libertad y por sus prácticas religiosas. "Este lucrativo comercio de seres humanos basado en el cautiverio y la deportación fue legitimado jurídicamente por la corona mediante la creación de un nuevo tipo de contrato: el asiento de negros." (Maya, 1998). Este consistió en dar permiso a una persona para que transportara a seres humanos, y ser vendidos como "mercancías".

Por lo anterior, se constituyó en la ciudad mayoritariamente habitada por africanos, africanas y sus descendientes. Muchos de los afrodescendientes fueron traídos de "contrabando" a las Américas, y otros como demasía. Que es un acuerdo entre la corona y el esclavizador, que era transportar diez por ciento más de lo autorizado por la autoridad colonial, para asegurar que la "mercancía" llegara completa a su destino. (Maya, 1998).

La ciudad de Cartagena, actualmente cuenta con una población aproximada de 955.250 habitantes, siendo la quinta ciudad más poblada de Colombia, que además, está dividida en tres localidades o alcaldías menores, incluidas las zonas rurales e insular de sus territorios. Además de acuerdo con el censo del Departamento Administrativo Nacional de Estadísticas (DANE) para el 2007 el 35.6\% de la población de Cartagena se auto reconoció como negros.

\section{Colombia un país de leyes y su no aplicación desde la perspectiva étnica}

Desde 1821 con la ley de parto, se dan los primeros pasos para el reconocimiento de seres humanos. A partir de esta fecha los niños y niñas nacidos de los africanos y africanas eran libres. Después de treinta años, en el año de 1851, en el gobierno de José Hilario López, se lleva a cabo la eliminación de la esclavización de los africanos y africanas. Esta norma, comienza a tener aplicación a partir del primero de enero de 1852.

En 1993, la ley 70 hace un reconocimiento a las comunidades afrodescendientes o comunidades negras. A raíz de la reglamentación de esta ley, existen en un sinnúmero de decretos, para la protección de su territorio en el decreto 1745 del 1995; la educación con el decreto 804 del 1995, participación en el Congreso de la República con la ley 649 del 2001.

Siguiendo lo anterior, también se promulga la ley antidiscriminación racial y contra el racismo, expedida como la 1482 del 2011, "por medio de la cual se modifica el código 
penal y se establecen otras disposiciones". La ley es explicita y establece que: "Actos de Racismo o Discriminación por razón de su raza, nacionalidad, sexo u orientación sexual, incurrirá en prisión de doce (12) a treinta y seis (36) meses y multa de diez (10) a quince (15) salarios mínimos legales mensuales vigentes (Artículo 134 ${ }^{\mathrm{a}}$ ). A pesar de la existencia de la ley, no se conocen casos en donde se haya aplicado en la ciudad de Cartagena, pero si prevalen las denuncias de racismo y discriminación en la ciudad.

\section{Una mirada desde los periodistas: El racismo y la discriminación racial en Cartagena}

Los periodistas del diario El Universal, tienen un conocimiento general sobre el racismo y la discriminación racial. A pesar de ser un tema que ha estado en debates en diversos espacios y momentos de la ciudad. Para ellos se entiende por racismo y discriminación racial, tres categorías sencillas, las cuales apuntan a: desprecio, rechazo y exclusión.

La primera está basada en ofensas, humillaciones y burlas que se representa en palabras, gestos y signos. De acuerdo con estos conceptos planteados, se analiza que la discriminación racial está pensada en la prensa escrita de diferentes ángulos; pero, no se reflejan en los textos escritos que más adelante se analizan. Por consecuencia no se evidencia una mirada amplia en sus respuestas con respecto a esa categoría, como es el desprecio. Para la periodistas de El Universal J. Corrales "es todo lo que se hace con palabras, con gestos, utilizando cualquier signo que vaya en contra o haga sentir mal a una persona", (Entrevista, 8 de mayo de 2014).

Asimismo, el segundo concepto que es el rechazo, lo plantean como la no aceptación a la diferencia, en una realidad que "afea" e incómoda a quienes se resisten a compartir con sus diferentes. Así lo plantea Pallares, que "el rechazo hacia la diferencia, o el rechazo hacia el no conocer la diferencia de las otras personas" (Entrevista, 8 de mayo de 2014). Cuando se escucha este argumento, se puede entender la discriminación en todos los aspectos, porque no sólo en lo racial. Debido que la diferencia es en todos los aspectos de la vida de los seres humanos. Por lo tanto es un concepto generalizado en el que estos no profundizan.

Hasta aquí, este análisis de la discriminación racial desde la concepción de los periodistas, está pensado desde una perspectiva económica y social, más no de una mirada étnica y fenotípica. Asimismo plantea $P$. Torres, que "una de las más grandes muestras de subdesarrollo, que todavía estamos padeciendo aquí en Cartagena, es la discriminación racial" (Entrevista, 8 de mayo de 2014).

Por último, la exclusión, como tercera categoría que recoge con mayor claridad la discriminación racial por medio del color de la piel y la diversidad étnica. La cual está argumentada en las manifestaciones de no querer compartir el espacio entre diferentes, por sus rasgos fenotípicos. Por esto hacen énfasis en el color de piel, que 
define el grupo étnico al que se pertenece, estos planteamientos son particularmente de los periodistas R. Álvarez y S. Álvarez (Entrevista, 8 de mayo de 2014).

Estas categorías no se presentan en las pocas noticias que se abordan. Además, no hay escritos que apunten a sensibilizar a la comunidad en su comportamiento. Igualmente no hay una claridad conceptual de la discriminación racial y el racismo en las respuestas que se reciben de los periodistas.

El siguiente testimonio, reafirma el planteamiento:

Aquí en El Universal, no era costumbre y lo digo con mucha modestia y con mucha humildad, no era costumbre ventilar casos de racismos, ni hablar de discriminación racial, ni mucho menos, ni de discriminación de ningún tipo. Eso empezó a darse del año 95 para acá. (R. Álvarez, Entrevista, 8 de mayo de 2014).

Basado en lo anterior y tratando de comprender el grado de consciencia que tienen los periodistas sobre la discriminación racial, se puede dilucidar con sus respuestas, que para muchos, la discriminación está más en el pensamiento de las comunidades negras que la realidad actual en Cartagena. Esto desde luego, también se refleja en las noticias del diario el Universal, porque no hay una continuidad en la investigación de la publicación de los hechos de discriminación racial y racismo.

Las comunidades negras que a través de la historia viven la discriminación racial son sensibles a las acciones, debido a que han aprendido a diferenciar una actitud de aceptación y una de rechazo. Esto, para algunas personas en la práctica se argumenta, o se plantea como acto de resentimiento social por parte de los negros y negras (Munera, 2004).

\section{La percepción de la comunidad afrodescendiente sobre el abordaje de la discriminación racial}

Las noticias que mayormente se presenta en los diarios, son aquellas que tiene un impacto en la industria cultural del comercio. Debido a que los diarios tienen unas metas de ventas, y de cautivar a muchos suscriptores que garanticen un aumento de las acciones del mismo, además de tener un rating de cobertura (L. Rodríguez, comunicación personal, 15 de marzo de 2014). Por lo tanto, el abordar una noticia de discriminación está sujeto a la persona que haya sido discriminada racialmente.

Son muchos los elementos que plantean los líderes y lideresas de las comunidades sobre su percepción de cómo se abordan las noticias en el diario. Desde plantear "que no hay una voluntad expresa del diario El Universal". Esto debido a la forma, cuando se publican, cómo se presentan los hechos de discriminación racial o racismo que a diario suceden en la ciudad, (K. Gutiérrez, Entrevista, 10 de marzo de 2014). 
Aunque para la comunidad negra, hay una tácita y ligera limitación de la participación de estos en las noticias desde la perspectiva de pueblo étnico. De acuerdo con Van Dijk (2005), esta es una práctica que se denomina "nuevo racismo", en el que se niega la práctica de racismo o discriminación racial a pesar que cotidianamente se esté evidenciando, debido que se ha naturalizado la práctica en el día a día. Debido que las noticias que se presentan como discriminación racial, son planteadas desde un enfoque del suceso, porque lo presentan como un simple hecho de ciudad, simple hecho cotidiano, contribuyendo con esto a la naturalización de la discriminación racial en los diversos contextos de la ciudad (A. Cassiani, Entrevista, 21 de abril de 2014).

Por lo tanto, la prensa escrita tiene o debe tener un carácter de formación e información, debido que las noticias publicadas son investigación de diversos niveles, las cuales cuenta en la actualidad con más de una fuente que permita al lector debatir el tema, además para que haya "imparcialidad y objetividad" del periodista o comunicador.

Para algunos líderes y lideresas su argumento se basa en una actividad académica y cultural que se realiza en el mes de mayo. Plantean que uno de los pocos eventos que se aborda es la movilización que se ha denominado la Kandanga . Para N. Magallanes;

No hay un rescate entre los logros y satisfacciones que ha tenido el pueblo afro, $y$ son muy mínimo la cobertura que se le da, a duras penas cuando hay movilización en el marco de la semana de la afrocolombianidad se deja ver algunos momentos, porque ya les toca, porque se ha afectado toda la ciudad y es evidente el auge, por lo tanto lo muestra, pero en el día a día limita la participación de los afros. (Entrevista, 20 de marzo de 2014).

Es de esperar que la crítica continua a la cobertura de las diversas noticias de las comunidades negras, es una constante la participación y la visibilización que exigen los líderes y lideresas. Los hechos de noticias de discriminación y racismo que han sido abordados por el diario son cubiertos por sus impactos de carácter nacional, lo que hace evidente el cubrimiento de la noticia desde una lógica de consumo por el diario El Universal, (M. Obeso, Entrevista, 4 de mayo de 2014). Un ejemplo de ello, fue el acto de discriminación racial de la cual fue víctima la ex reina para el concurso nacional de la belleza en Cartagena, por el departamento de San Andrés, Providencia y Santa Catalina, Jackelinne Howard en el aeropuerto internacional "Rafael Núñez" de Cartagena, N. Magallanes (Entrevista, 20 de marzo de 2014).

Finalmente se analiza que de acuerdo con los líderes y lideresas de la comunidad negra, la cobertura del debate de la discriminación racial y racismo desde el diario El Universal, son muy tímidos y no se ahonda en la profundidad de los hechos. Además, surge la crítica porque se presenta como el suceso cotidiano de la ciudad, en el cual se está naturalizando una práctica ofensiva contra la persona, sin importar su color 
de piel, su concepción religiosa, económica, política y social. Por lo tanto, "en la manera que se genera información se configuran valores colectivos, relaciones sociales e ideas específicas de diversidad cultural." (Observatorio contra la Discriminación y el Racismo: Ministerio del Interior, 2012).

\section{El abordaje de las noticias referidas a la discriminación racial}

Realizar un análisis de las noticias referidas a las comunidades negras, habría que particularizar una sección del diario El Universal. Para esto se escogió a la segunda de mayor importancia que recoge todos los hechos de la ciudad, que se denomina "Cartagena". Con respecto a la cobertura noticiosa en la sección "Cartagena", ha arrojado 67 noticias relacionadas con la comunidad negra en el período de 2012 y 2013, en todos los aspectos que a esta se refieren. Cuando se utiliza las categorías afrodescendientes, negros o palenqueros. Este análisis se subdividió en cinco categorías para abordar las noticias. Pero sólo se desarrollará en este artículo la de nuestro interés, la discriminación racial y racismo.

En este análisis de prensa escrita, para el tema de la discriminación racial o racismo, se han encontrado nueve noticias que se refieren a la problemática. De éstas, dos son del tema del debate que suscitó la discriminación racial a una ex funcionaria de la Alcaldía de Cartagena, ex directora del Instituto de Patrimonio y Cultura de la ciudad. En la que en el mes de febrero de 2012, hizo una reserva en un restaurante del centro histórico. A pesar que sus invitadas llegaron a tiempo a la cita, estas fueron lanzadas a un rincón en del restaurante, en la cual, las mujeres se sintieron "discriminadas", porque no estaba a la altura de lo que esperaban. Esta "discriminación", de acuerdo con la nota de prensa, fue para darles prioridad a unos invitados de una organización de los grandes gremios económicos del país. En la nota periodística, no se dice si las mujeres son discriminadas por su color de piel, pero se deja entre ver que es por la imponencia económica que tiene el grupo que llega después.

La noticia fue abordada el día siguiente, con la versión de la parte denunciada, es decir, los propietarios del restaurante. Quienes presentaron unas declaraciones que cada persona podrá interpretar de manera particular.

Mi esposa y yo estamos muy apenados, pero lo que sucedió fue que al restaurante llegaron unos señores del grupo empresarial Ardila Lülle y, cuando ellos llegan, lo hacen con un grupo de escoltas que dificulta todo. Por eso se les pidió a las señoras que ocuparan otro sitio y cuando yo quise salir a hablar con ellas ya se habían ido (Álvarez, 15 de Junio 2012, pág. 5A).

Los propietarios del restaurante reconocen que les solicitaron a las señoras ocupar un espacio diferente al cual se le había asignado a su llegada. La nota no aborda la noticia más profunda, se queda corta en el debate de lo que han denunciado las 
mujeres que se sintieron agredidas por los dueños del restaurante. A pesar de ser una mujer de influencia en la ciudad, el diario es tímido en la problemática. Una porque la agredida decidió no continuar el debate público o porque que quienes estaban del otro lado pidieron silenciar al diario. Otra opción es que el diario cree haber debatido el tema con las partes.

Asimismo, en estas nueve (9) noticias de discriminación que se registran durante los dos años de análisis, sólo tres hacen referencia a la discriminación racial o racismo a las comunidades negras. Las cuales son las siguientes; "Dice investigación académica. Lo afro en la agenda noticiosa, otra exclusión" (Álvarez, julio de 2012, pág. 5A), la segunda nota es otra investigación que "Dice Escuela Nacional Sindical. Cartagena, la más atrasada en trabajo digno para afros" (Álvarez, agosto de 2012, 5A) y la tercera nota es "La idea nació en Cartagena y se lanzó en Cali. En marcha el Consejo Laboral Afrocolombiano" (Álvarez, agosto de 2012, pág. 5A) y por último de la cuarta nota es "Evento afro en UniCartagena" (Álvarez, marzo de 2013, pág. 04), esta misma nota fue publicada dos días después. En una columna derecha que tiene el diario El Universal, la cual decía:

Hoy, desde las dos de la tarde, en el paraninfo de la universidad de Cartagena, se desarrollará el panel "El derecho a no ser discriminado", en el marco del "Día mundial contra el racismo, la exclusión y discriminación racial”, también se hará plantón “ “Fin del Racismo ya!; en la plazoleta Benkos Biohó. (21 de marzo 2013, pág. 05)

Estas notas, son más desde una perspectiva académica. Aunque hay una con un gran interés por el enfoque laboral que plantea la Escuela Nacional Sindical basada en estudios de la relación de vínculo contractual de las personas negras en las empresas de la ciudad. Particularmente en el libro "Precario pero con trabajo: otros están peor" y tiene como subtítulos "Déficit del trabajo decente en la población afrocolombiana. Cartagena, Buenaventura, Cali y Medellín 2009-2010" del investigador Guillermo Correa. En esta investigación se "recalcó que [Cartagena] es la ciudad que más ha desviado lo laboral para los afros, haciendo énfasis en la identidad, en el folclor y las tradiciones, demostrando con ello que la ciudad tiene menos preguntas frente a la discriminación" (Álvarez, agosto de 2012, pág. 5A).

Las últimas dos noticias encontradas es importante resaltarlas. Una que está referida a una iniciativa del Ministerio del Interior Nacional de Colombia. El titular de la nota dice así: "Con apoyo del Ministerio del Interior. Se abre paso Observatorio de discriminación y violencia" (Redacción local, mayo de 2013, pág. 4A). En uno de sus apartes la nota asegura que la realidad de la ciudad es grave. Por lo tanto es urgente y necesaria esta iniciativa. "Las cifras siguen demostrando que Cartagena es una ciudad agresiva frente a las diferencias raciales y sexuales y por ello logró tener la atención por parte del Ministerio del Interior se ponga en marcha esta iniciativa" (Redacción local, mayo de 2013, pág. 4A). 
La segunda es una sencilla, pero importante nota que habla de la normatividad de discriminación racial, titulada: "Foro este fin de semana en Cartagena. La discriminación es un delito" (Redacción local, agosto de 2013). Colombia es un país que se ha caracterizado por tener normas en todos los ámbitos, así lo han planteado diversos juristas. A pesar de las investigaciones que se vienen realizando constantemente en la ciudad, El Universal no aborda la problemática de la discriminación racial que vive la ciudad de forma abierta y práctica. Sólo se dedica a relatar uno que otro acto de discriminación racial o racismo, pero no presenta propuestas concretas y profundas que hagan de este tema un debate en lo público y privado.

\section{Mecanismos de eliminación de estereotipos y prejuicios que son racista y discriminadores}

Presentar propuestas de mecanismos que eliminen los prejuicios y estereotipos en la cotidianidad de Cartagena desde el diario El Universal, es fundamental porque se debe partir de la visibilización de las comunidades negras. La conceptualización de discriminación racial y racismo permite ampliar el debate de cómo se puede educar y sensibilizar a la población en general, para que esta práctica no se promueva en ambas direcciones; ni en contra de los negros, ni en contra de los mestizos e indígenas. Por lo tanto, la discriminación racial, es entendida como la no aceptación de la diferencia en las personas, particularmente a los negros y negras en Cartagena. Además de observar, como un acto que puede ser voluntario e involuntario porque niega a la otra persona, muchas veces por el desconocimiento que se tiene de las demás personas.

Por consiguiente, las propuestas que se han percibido de acuerdo con el diálogo con la comunidad negra corresponde a: desarrollo de una columna permanente, una franja de noticias que recoja los diversos aspectos de discriminación y racismo, igualmente una revista que se incluya la realidad cotidiana de los negros y negras. Estos espacios permitirán visibilizar el aporte de los africanos en la época colonial, asimismo de la comunidad negra en la actualidad.

\section{Conclusiones}

No existe en el diario El Universal una política clara para trabajar el tema de la discriminación racial y racismo, a pesar de ser Cartagena una ciudad con un alto nivel de discriminación racial y racismo. Falta sensibilidad de los periodistas frente a la discriminación racial, no es un tema relevante al que se le dedica tiempo. Por lo que se cree que con el cubrir algunas noticias es suficiente.

Es necesario que el Diario el Universal asuma una postura crítica y constructiva frente al papel de las comunidades negras o afrodescendientes, como grupos organizados que trabajan por la reparación, rescate de su identidad y cumplimiento de sus derechos con enfoque diferencial. 
Finalmente la práctica de la discriminación racial en el nivel micro como lo plantea Van Dijk, (2001) se presenta en todos los ámbitos de la vida cartagenera, por lo tanto debe ser combatida desde la institución educativa (M. Obeso, Entrevista, 2014; R. Álvarez, Entrevista, 2014), hasta los diversos espacios sociales que permita el fortalecimiento y reconstrucción de la identidad.

\section{Lista de referencia}

Alsina, M. (2001). La Comunicación Intercultural. portal de la comunicación, consultado 29/og/2012, en: http://www.portalcomunicacion.com/esp/pdf/aab_lec/ rodrigo.pdf

Álvarez, R (9 de julio de 2012). Lo afro en la agenda noticiosa, otra exclusión. El Universal, Cartagena. Pág. 5A.

Álvarez, R. (7 de marzo de 2013). Desde el viernes 1 de marzo. Polémica por invasión de lote en corregimiento de Santa Ana. El Universal, Cartagena. Pág. 4A.

Álvarez, R. (13 de agosto de 2012). La idea nació en Cartagena y se lanzó en Cali. En marcha el consejo laboral afrocolombiano. El Universal, Cartagena. Pág. 5A.

Álvarez, R. (15 agosto de 2012). Déficit del trabajo decente en la población afrocolombiana. El Universal, Cartagena. Pág. 5A.

Álvarez, R. (15 de junio de 2012). Por internet cancelan reunión. Comunidades afros exigieron al alcalde respeto. El Universal, Cartagena. Pág. 4A.

Álvarez, R. (19 de marzo de 2013). Evento afro en UniCartagena. El Universal, Cartagena. Pág. 04 .

Álvarez, R. (6 de agosto de 2012). Dice escuela Nacional Sindical. Cartagena, la más atrasada en trabajo digno para afros. El Universal, Cartagena. Pág. 5A.

DANE. (2007). Colombia una nación multicultural. Su diversidad étnica. (Recuperado: 12/11/2013) www.dane.gov.co/censo/files/presentaciones/grupos_etnicos.pdf

Del Cid, V. M. (2010). Glosario de Ciencias Sociales y pueblos Indígenas. Edición, Fredy Leonel Valiente, Managua, Nicaragua.

Giddens, (2000). Etnicidad y raza. En: Sociología. Alianza Editorial, Tercera edición. (pág. 277-315) Madrid. 
Goetz, J., \& LeCompte, M. (1988). Etnografía y diseño cualitativo en investigación educativa. Madrid: Morata.

León, L. (2012). Imaginarios sobre lo étnico-racial negro en la agenda noticiosa. Un pretexto para seguir cuestionando-nos. Cartagena: Universidad de Cartagena, Facultad de Ciencias Sociales y Educación.

Maya, L. A. (1998). Demografía Histórica de la trata por Cartagena 1533-1810. En L. A. Maya, Geografía humana de Colombia. Los Afrocolombianos Instituto Colombiano de Cultura Hispánica (pág. 11-52). Bogotá.

Ministerio del Interior (2012). Segundo Informe: Discriminación laboral en Cali. Un acercamiento desde la desigualdad socio-demográfica en el área metropolitana. Bogotá: Dirección de asunto de comunidades negras, afrocolombianas, raizales y palenqueras, Ministerio del Interior de Colombia.

Ministerio del Interior (2012). Segundo Informe: Discriminación laboral en Cali. Un acercamiento desde la desigualdad socio-demográfica en el área metropolitana. Bogotá: Dirección de asunto de comunidades negras, afrocolombianas, raizales y palenqueras, Ministerio del Interior de Colombia.

Munera, A. (2004). Discriminación Racial: 'No se puede tapar el sol con un dedo'. En El Universal, miércoles 23 de junio, Cartagena de Indias.

Redacción Local. (12 de agosto de 2013). Foro este fin de semana en Cartagena. La discriminación es un delito. El Universal, Cartagena. Pág. 5A.

Redacción Local (16 de mayo de 2013). Con apoyo del Ministerio del Interior. Se abre paso Observatorio de discriminación y violencia. El Universal, Cartagena. Pág. 4A.

Restrepo, E., \& Rojas, A. (2010). Inflexión decolonial: fuentes, conceptos y cuestionamientos. Popayán: Universidad del Cauca.

Van Dijk, T (2001). Discurso y racismo. En: Persona y Sociedad. Editores, Universidad Alberto Hurtado, Instituto Latinoamericano de Doctrina y Estudios Sociales ILADES. Traducido por Christian Berger. Escuela de Psicología. (Pág. 191-205).

Van Dijk, T (2005). Nuevo racismo y noticias. Un enfoque discursivo. En M. Nash, R. Tello, \& N. Benach, Inmigración, género y espacios urbanos. Los retos de la diversidad (págs. 33-55). Barcelona: Bellaterra.

Van Dijk, T. (1999). Análisis crítico del discurso. En: Anthropos 186, septiembre-octubre, (pág. 23-36). Barcelona. 